\title{
Fail-Safe Methods for Paratransit Safety
}

\author{
Joanne M. Sulek and Mary R. Lind
}

North Carolina A\&T State University

\begin{abstract}
The purpose of this study was to illustrate that a systems approach to transit safety can be used to develop a methodology to fail-safe or mistake-proof paratransit operations. The fail-safe methodology illustrated in this article was implemented in a small rural transit system in the southeast U.S. Results demonstrated that safety problems often stem from an interaction of service errors and system components. Results also revealed that fail-safe methods that target specific user groups are more effective than more general methods.
\end{abstract}

\section{Introduction}

Mistakes occur in all paratransit systems. Some of these mistakes may lead to significant service failures that could endanger passengers, drive up insurance costs, diminish productivity, and damage the transit system's reputation. Advanced computer software and state-of-the-art equipment do not insulate paratransit systems from errors that could compromise service safety (Einstein 2001). Moreover, many transit systems, especially rural and small urban systems, cannot afford expensive technology or external consultants to help them mistake-proof operations.

Given increasing liability costs, paratransit managers need inexpensive yet effective error prevention techniques that are easy to understand and simple to imple- 
ment. To meet this need, this study developed a fail-safe methodology to help managers identify and correct mistakes before they generate significant safety problems. This fail-safe methodology represents a hands-on approach to reducing errors in service delivery. Like other quality management tools, fail-safe techniques have played a role in industrial quality programs for many years (Stewart 2003). In contrast to statistical process control methods, which require statistical analysis of large amounts of historical data, fail-safe techniques emphasize performance standards, worker empowerment, and information flows to prevent defects. This study will illustrate how an actual paratransit system used a fail-safe methodology to analyze the error generation and prevention process in its operations.

The next section provides an overview of the systems approach to the mistakeproofing process for service safety. A discussion of the research context and the methodology follows this overview. An application of the methodology in an actual paratransit system is then presented. The article concludes with the managerial implications of the study.

\section{A Systems Approach to Paratransit Safety}

The delivery of safe transit service requires a coordinated effort between transit workers and transit customers, as well as the effective use of technology and management and control systems (Prioni and Hensher 2000). Since a safe operation is the product of the entire transit system rather than a single component of the system, preventing mistakes that could endanger passengers or lead to injury, accidents, or property damage requires a systemwide approach (Sulek and Lind 2000). In describing their framework for service delivery, Chase and Bowen (1991) emphasized the need for a systems approach when analyzing and improving service operations and identified technology, systems and people as the three major components of service operations. This article will adopt Chase and Bowen's systems framework to study how potentially harmful mistakes may be generated in a paratransit system and how these mistakes could be prevented before they endanger system employees, the public, or property.

Like Chase and Bowen's (1991) framework, the systems approach that will guide this fail-safe study models technology, systems and people as the three major components of service delivery. In a paratransit system, the technology component includes vehicles, lift equipment, machinery, and tools, as well as facilities like garages and administrative offices. The systems component involves procedures 
and software for scheduling, routing, maintenance, transport, inventory, planning, and performance evaluation. The final component, people, encompasses both the service providers, such as drivers and office personnel, and community stakeholders, such as riders, local agencies, medical providers, and industries.

An effective fail-safe methodology should address all three system components and help the manager anticipate how these components might interact to produce errors that could endanger others or damage property. For example, if a driver lacks technical skills or knowledge, he may make a serious mistake in operating the van lift equipment and injure himself or the passenger (people-technology interaction). If the scheduling system does not capture critical information regarding a passenger (e.g., the rider is hearing impaired), the driver will not be forewarned of a potential safety problem (people-system interaction). If the maintenance scheduling software is not reliable, it may fail to schedule routine maintenance for a van. Poor maintenance could result in mechanical failure that may endanger the driver and riders (technology-system interaction). If the scheduling software does not remind a driver that it is time for a routine physical, a health problem may go unnoticed until driver impairment causes a traffic accident (people-system-technology interaction) (Figure 1).

\section{Figure 1. Systems Model of Paratransit Service Delivery}

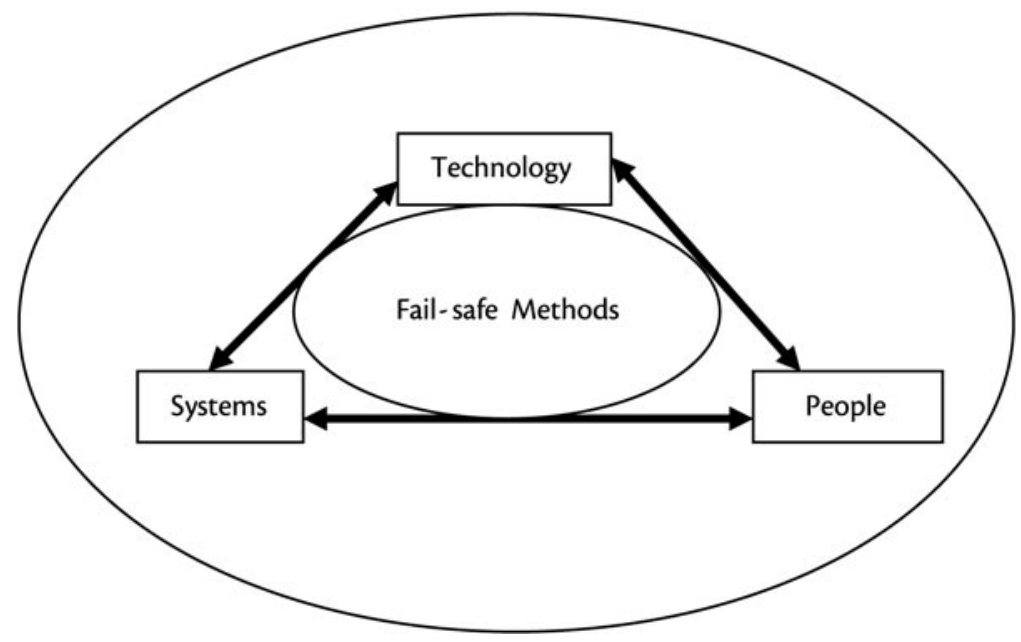


Not all service errors arise from an interaction of two or more system components. Some mistakes result from the people component alone (Friman et al. 1998). For instance, a dispatcher could jeopardize an elderly dialysis patient's health by not promptly notifying a van driver that the patient was ready for pick-up from the doctor's office. A driver may spend too long taking a break and later try to compensate for lost time by rushing passengers. A front-office worker may forget to notify a passenger about a change in rider eligibility status. These types of workergenerated mistakes clearly require fail-safe measures.

Fail-safe measures also apply to the behaviors and attitudes of paratransit customers. In many services, a significant proportion of problems stem from mistakes made by the customers themselves. Chase and Stewart (1994) identified three major sources of customer mistakes: (1) failure to understand and anticipate the customer's role during service delivery; (2) failure to follow instructions, remember crucial steps, or communicate service needs during the service process; and (3) failure to alert management about service problems once the service is complete. Since riders and other paratransit customers can make any of these mistakes, failsafe methods that target customer participation skills and information access can help promote paratransit safety.

In particular, elderly riders may benefit from such fail-safing efforts. The number of elderly citizens in the United States is expected to increase significantly as baby boomers age. Mobilty needs of the elderly are expected to increase as larger numbers of older adults try to lead active lives, despite age-related problems that impair driving skills (Rosenbloom 2001). Elderly drivers tend to experience high accident rates (Burkhardt 1999); moreover, even conservative projections indicate that, by 2030 , the number of fatalities in automobile accidents involving elderly drivers will quadruple the 1996 level (Hildebrand 2003; Burkhardt and McGavock 1999). Paratransit services that are safe and easy for elderly riders to use can reduce the need for older adults with serious health problems to drive. In addition, failsafe methods can help elderly riders use paratransit systems safely.

In addition to addressing the people, technology and systems components of service delivery, a fail-safe methodology must also analyze the relationships among the various stages in paratransit service. There are two arguments for modeling paratransit service as a multistage process. First, the consequences of the interactions among technology, people, and systems may vary with the service stage. For instance, if a dialysis patient unbuckled one of his safety belts during transport, serious injury could result if the driver had to slam on the brakes suddenly. If 
the van has already stopped at the dialysis center when the rider unbuckles the belt, risk to the patient is not nearly so great. Second, the stages of paratransit service are not independent of one another. What happens at one stage may affect service delivery a later stage. If unchecked, small mistakes made during an early, or upstream, stage of the service process may "snowball" into problems at a downstream stage (Perrow 1984) (Figure 2). These problems may involve minor incidents or catastrophic failure. For instance, if the first passenger on a route is late for pick-up, the driver may not be able to pick up other passengers on time. These other passengers could arrive late for their medical appointments or miss them entirely, thus endangering their well-being.

\section{Figure 2. System Failure/Snowball Effect}

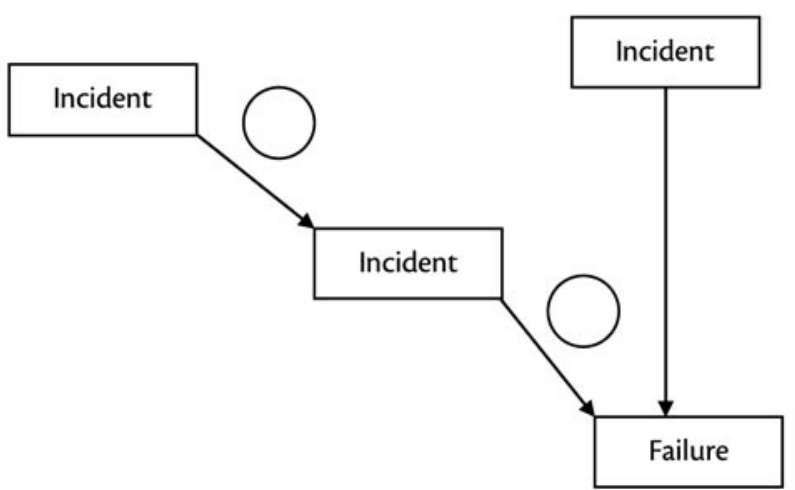

Although interdependency among service stages is quite common in many service operations, little research has been done to illustrate the effectiveness of a multistage approach to process improvement (Sulek 2004). However, a few recent articles in the service management literature have argued that a stage-by-stage analysis of a service operation can reveal problems that could be overlooked by organization-level analysis alone. For instance, Souteriou and Hadjinicola (1999) used a multistage approach to optimize customer perception with service delivery. Armstrong (1995) modeled the effect of service interventions in multiple service stages as a function of customer perceptions and service attributes at each stage. Sulek, Marucheck and Lind (2005) analyzed labor productivity in a multistage service process consisting of serially dependent stages. 
A fail-safe methodology based on multistage analysis can do more than help managers avoid routine errors; it can also help to prevent major service failures that appear to occur simply by chance. Perrow (1984) discussed such failures and concluded that many result from an unanticipated interaction of multiple errors that arise from multiple sources. These errors, taken individually, may not seem significant, yet their interaction can produce catastrophic consequences.

Since even small mistakes can cause major problems, paratransit managers cannot afford to be reactive or adopt a hit-or-miss approach in error prevention. Instead, managers need a more rigorous approach that will help them break the chain of service errors that can lead to safety problems or catastrophic service failures. The following section describes such a fail-safe methodology and discusses how it was used to mistake-proof operations at a small urban transit system.

\section{Research Context and Method}

A rural paratransit system located in western North Carolina served as the research context for this study. The system served an area covering 500 square miles and operated 27 lift vans. The system's exposure to safety problems had risen significantly over the past decade, with vehicle miles increasing from 325,000 miles per year to 750,000 miles per year and the number of passenger trips growing from 50,000 trips per year to 90,000 trips per year. Providing safe, dependable transport was a priority for the manager of this system. The manager realized that mistakes had led to accidents and service incidents in the past and decided to apply fail-safe procedures to aspects of operations that could compromise safety.

To begin the fail-safe effort, the manager and the authors used system records, the manager's expert knowledge, and process mapping to model service flows and identify key service stages or links. Problem areas that needed fail-safe attention were determined for the stages in the process map. An iterative process, as shown in Figure 3, was used to trace problem causes and devise and assess fail-safe solutions.

From this collaborative analysis, a fail-safe methodology was developed. The following activities constitute a continuous fail-safe process:

- Develop and revise a process map of service delivery. By indicating the individual service delivery stages, the process map will make it easier to determine where service problems occur (Chase and Stewart 1994). 


\section{Figure 3. Fail-Safe Process}

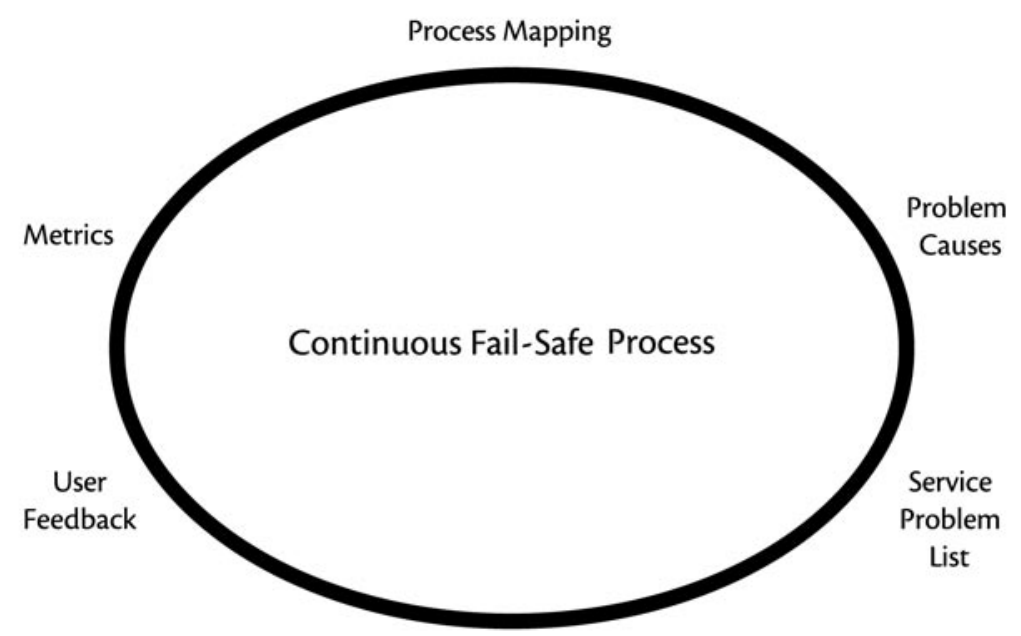

Solutions

- Create a list of service problems that occur at each service stage in the process map. Maintaining a list of problems and complaints as they arise will help with this step. Using this list, feedback from transit employees and customers, system performance metrics, and maintenance and repair records, the manager can anticipate future safety incidents and problems.

- Identify the causes or errors that could lead to the problems listed in the preceding step. Finding the causes often involves working backward through the process to identify the original mistakes that "snowballed" or escalated into downstream service failures.

- Devise fail-safe solutions to prevent the types of mistakes that were identified in the preceding step.

- Develop service performance metrics based on operating data to assess the effectiveness of the fail-safe methods.

- Gather feedback from service customers to assess quality of service delivery.

- Use the performance metrics and customer feedback to update the fail-safe methods and improve service performance. 
An initial activity in the fail-safe process involves charting all of the critical stages that service delivery entails. The process map should accomplish three important objectives: (1) trace the rider's participation in service delivery; (2) highlight critical back-office tasks; and (3) identify all major points of interaction between transit employees and riders. It is important to meet all three objectives because riders' mistakes, employees' errors, and problematic interactions between transit workers and customers all contribute to safety problems.

Figure 4 presents a process map for paratransit services provided by the small system that served as the research context in this study. The process map depicts eight critical stages in this paratransit operation: (1) the rider's initial request for service, which is shown as the Rider-Dispatcher link on the diagram; (2) confirmation that the rider is eligible for services, which involves the Department of Social Services (DSS)/Agency-Dispatcher link; (3) ride scheduling, which involves the Dispatcher-Scheduler link; (4) manifest creation, which involves the Scheduler-Driver link; (5) rider pick-up, which involves the Driver-Rider Pick-Up link; (6) transport of riders to their appointments, which is shown as the Rider-Transport link; (7) rider pick-up after their appointments, which involves the Doctor's Office-Driver link; and (8) transport of the riders back home, which is shown as the Return Trip link.

The next phase of the fail-safe process involves an examination of each critical link in transit service delivery. A close look at each link can help the manager

\section{Figure 4. Transit Process Flow}

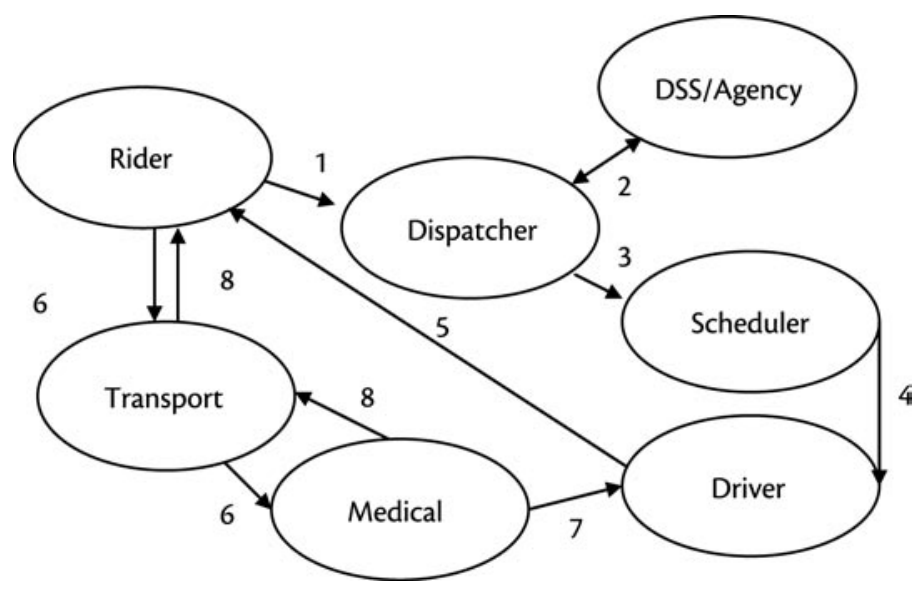


determine the types of service problems that could occur at each stage and make it easier to identify the mistakes that caused them. The analysis should include all service problems - not just apparent safety problems-because an interaction of even minor service errors can sometimes generate serious incidents. Tables 1 and 2 illustrate the problem/cause analysis phase for two service links: the Driver-Rider Pick-Up link and the Transport link. (Similar tables were developed for the other service links but are not shown.)

\section{Table 1. Driver-Rider Pick-Up Link: Service Problems and Mistakes}

\begin{tabular}{|c|c|}
\hline Problems & Causes \\
\hline \multirow[t]{6}{*}{ Driver is running behind schedule } & Schedule creep \\
\hline & $\begin{array}{l}\text { Driver misjudged pick-up time and travel } \\
\text { time }\end{array}$ \\
\hline & Rider provided the wrong pick-up address \\
\hline & Time of day \\
\hline & Adverse weather conditions \\
\hline & $\begin{array}{l}\text { Delays en route-accidents, road } \\
\text { construction, etc. }\end{array}$ \\
\hline Driver must wait for rider & $\begin{array}{l}\text { Rider does not understand that he/she must } \\
\text { be ready prior to pick-up time }\end{array}$ \\
\hline \multirow[t]{3}{*}{ Rider no -show } & Rider misunderstanding \\
\hline & Nursing home does not have patient ready \\
\hline & Rider forgot to cancel ride appointment \\
\hline \multirow[t]{2}{*}{ Rider has mishap while boarding } & Physical barrier to safe boarding \\
\hline & Rider not able to board due to illness \\
\hline Driver does not allow rider to board & $\begin{array}{l}\text { Parent brings along child without approved } \\
\text { child seat }\end{array}$ \\
\hline \multirow[t]{2}{*}{$\begin{array}{l}\text { Driver needs help in getting rider safely on } \\
\text { board }\end{array}$} & $\begin{array}{l}\text { Inadequate, homemade ramps at } \\
\text { passenger's home }\end{array}$ \\
\hline & $\begin{array}{l}\text { No ramp and no sidewalk so driver cannot } \\
\text { push wheelchair from door to vehicle }\end{array}$ \\
\hline \multirow[t]{5}{*}{ Paratransit van cannot get near the house } & $\begin{array}{l}\text { Tree limbs obstructing driveway } \\
\text { Ruts in driveway }\end{array}$ \\
\hline & Fallen trees in driveway \\
\hline & Driveway too long to drive down \\
\hline & Driveway too steep \\
\hline & $\begin{array}{l}\text { Rider did not inform the dispatcher of } \\
\text { barriers to boarding the vehicle }\end{array}$ \\
\hline Passenger is not aware that van is waiting & $\begin{array}{l}\text { Hearing-impaired rider does not hear driver } \\
\text { blowing the horn and has not informed the } \\
\text { dispatcher about the impairment }\end{array}$ \\
\hline
\end{tabular}


In the Driver-Rider Pick-Up link, both riders and drivers face such service problems as late pick-ups, boarding mishaps, and physical barriers to boarding. As Table 1 illustrates, these problems stem from a variety of causes.

Riders can cause pick-up delays if they are not ready to leave when the van arrives, if hearing impairment prevents them from hearing the driver blowing the horn, or if they simply forget to cancel their ride appointments. Agencies like nursing homes also cause delays and no-shows if they do not have patients ready for transport when the van arrives. All of these mistakes involve the people component of the service system. On the other hand, there are a number of other causes for late pick-ups that are beyond an individual's control. These include heavy traffic, accidents, road construction, and adverse weather conditions. Schedule creep also contributes to late pick-ups.

Boarding mishaps can occur if riders who use wheelchairs rely on inadequate homemade ramps to help them exit their homes. Such ramps can easily collapse, injuring both the passenger and the driver. Without an adequate ramp, a driver may require a great deal of extra assistance with the passenger. In some cases, it may be impossible to get the rider on board safely, and the driver may have to refuse service to the passenger. A driver will also refuse service when parents try to bring children on board without approved safety seats. Both of these problems involve both the technology and people components of service delivery, since rider ignorance and faulty equipment can diminish safety.

Sometimes a driver in this paratransit operation cannot get the van close enough to the rider's home for a pick-up. A number of physical barriers can block safe access to a rider's home. For instance, fallen trees or tree limbs may obstruct the driveway; the driveway itself may be too steep, too winding, or too long to travel over safely; or the road surface may contain deep ruts or be too muddy. Drivers may find that even if a driveway is fairly safe, there is no way to easily push a wheelchair across the passenger's yard to the van. A driver may need a great deal of extra help in conveying a wheelchair rider to the van if no sidewalks are available.

Table 2, which shows the Rider-Transport link, describes the kinds of problems a passenger might experience during an actual ride. The worst problems include traffic accidents, which stem from poor driving technique by the van operator; driver inattention, driver impairment and on-board distraction; passenger injuries, which result from traffic accidents; failure to secure passengers in their seats; and passengers' misunderstanding of the rider's role during transit. At this paratransit system, some wheelchair riders have been injured after unfastening seat belts and 


\section{Table 2. Transport Link: Service Problems and Causes}

\begin{tabular}{|c|c|}
\hline Problems & Causes \\
\hline \multirow[t]{10}{*}{ Traffic accident } & Following too closely \\
\hline & Driving too fast \\
\hline & Ignorance of traffic laws \\
\hline & Unable to read or comprehend English well \\
\hline & Erratic speed changes \\
\hline & Erratic direction changes \\
\hline & Inattentive driver \\
\hline & Poor road conditions \\
\hline & On-board distractions \\
\hline & Driver impairment \\
\hline \multirow[t]{5}{*}{ Ride is not smooth } & Vehicle suspension \\
\hline & Tire failure \\
\hline & Sudden stops \\
\hline & Quick starts \\
\hline & Sudden or fast turns \\
\hline \multirow[t]{3}{*}{ Temperature is too hot/cold } & Driver inattention \\
\hline & Inadequate equipment \\
\hline & Equipment malfunction \\
\hline \multirow[t]{4}{*}{ Passenger creates disturbance } & Rude passenger behavior \\
\hline & $\begin{array}{l}\text { Passenger misunderstands rider } \\
\text { responsibilities and rules of travel }\end{array}$ \\
\hline & Passenger is frightened \\
\hline & Passenger is mentally unstable \\
\hline \multirow[t]{5}{*}{ Passenger injuries } & Wheelchair not properly secured \\
\hline & $\begin{array}{l}\text { Seat belt and shoulder strap not securely } \\
\text { fastened }\end{array}$ \\
\hline & $\begin{array}{l}\text { Children not secured in appropriate child } \\
\text { safety seats }\end{array}$ \\
\hline & $\begin{array}{l}\text { Passengers do not understand } \\
\text { responsibilities }\end{array}$ \\
\hline & Safety strap left in the aisle \\
\hline \multirow[t]{3}{*}{ Vehicle breakdown } & Equipment malfunction \\
\hline & Poor preventive maintenance \\
\hline & Hazardous environment \\
\hline \multirow[t]{2}{*}{ On-board medical hazard } & Passenger illness/accident \\
\hline & Driver illness/accident \\
\hline
\end{tabular}

straps while the van was nearing the dialysis center. These passengers thought they were being helpful by speeding up the unloading process and did not realize that their behavior was inappropriate and unsafe until it was too late. To a large extent, these problems involve the people component of service delivery. 
Vehicle breakdowns and equipment malfunction can also give the impression that a ride is not a safe one or can lead to accidents. These problems may stem from poor preventive maintenance, unsuitable operating environments (such as badly rutted dirt roads), or inadequate equipment (such as an air conditioning system that is too small to cool the van if the doors are opened frequently). These types of problems pertain mostly to the systems and technology components of service delivery.

Even if a passenger considers a ride safe, he or she may find it unpleasant. This can occur if the driver is rude or unhelpful to passengers, if the ride is not smooth, or if fellow passengers are disruptive or threatening. The passenger may also believe that the service is too slow. While poor road conditions can make a trip seem longer, a driver's failure to stay on schedule can also delay a trip. The people component of service delivery contributes to many of these service problems.

\section{Development of Fail-Safe Methods}

Once a manager identifies mistakes that cause service problems, fail-safe methods can be developed to reduce the chance of service errors. These fail-safe methods may involve improving access to information, instituting some new operating procedures, and modifying worker or rider behavior.

As Table 3 shows, the chief causes of late pick-ups and boarding problems on the Driver/Rider Pick-Up link stem from schedule creep, adverse road or weather conditions, rider mistakes, and physical barriers to boarding. Better training of drivers in the importance of on-time pick-ups may help reduce schedule creep. Reduction of the number of no-shows can also help diminish schedule creep. To help minimize no-shows, the dispatcher at this system could phone elderly riders the day before their appointments to remind them of the pick-up time. The dispatcher could also phone nursing homes with high no-show rates 10 minutes before scheduled pick-ups and ask personnel to have the patient ready for pickup. In the event of adverse travel conditions, the dispatcher at this system could call the doctor's office to try to reschedule the rider for a later appointment or might call the rider to cancel the pick-up if the roads are unsafe. The dispatcher also can help prevent some of the riders' mistakes by asking them to be ready one hour early for pick-ups on long routes or by reminding a parent to bring along an approved child's seat if his or her child will be riding in the van. 


\section{Table 3. Driver/Rider Pick-Up Link: Problem Causes and Fail-Safe Solutions}

\begin{tabular}{|c|c|}
\hline Causes & Fail-Safe Solutions \\
\hline \multirow[t]{3}{*}{ Schedule creep } & Minimize no-shows \\
\hline & $\begin{array}{l}\text { Greater emphasis on time pick-up in driver } \\
\text { training classes }\end{array}$ \\
\hline & Monitor drivers' driving times \\
\hline \multirow[t]{2}{*}{ Time of day } & Add extra van \\
\hline & Choose different routes \\
\hline \multirow[t]{2}{*}{ Adverse weather conditions } & $\begin{array}{l}\text { Dispatcher calls rider to cancel pick-up if } \\
\text { roads are dangerous }\end{array}$ \\
\hline & $\begin{array}{l}\text { Post notice on local radio, TV, and cable } \\
\text { TV stations }\end{array}$ \\
\hline $\begin{array}{l}\text { Delays en route - accidents, road } \\
\text { construction, etc. }\end{array}$ & $\begin{array}{l}\text { Dispatcher calls doctor's office to see if } \\
\text { rider can be late for appointment }\end{array}$ \\
\hline \multirow{5}{*}{$\begin{array}{l}\text { Rider does not understand that he/she must } \\
\text { be ready prior to pick-up time }\end{array}$} & DSS representative \\
\hline & Reminder cards for riders \\
\hline & $\begin{array}{l}\text { Dispatcher gives nursing home a phone call } \\
10 \text { minutes prior to van arrival }\end{array}$ \\
\hline & $\begin{array}{l}\text { Dispatcher gives the rider a window on } \\
\text { pick-up time when he or she calls for a ride }\end{array}$ \\
\hline & Dispatcher reminder \\
\hline Rider misunderstanding & DSS/agency representative \\
\hline Rider forgets to cancel ride appointment & DSS/agency representative \\
\hline \multirow[t]{2}{*}{ Physical barrier to safe boarding } & Volunteer agencies \\
\hline & City or county services \\
\hline $\begin{array}{l}\text { Parent brings along child without approved } \\
\text { child seat }\end{array}$ & $\begin{array}{l}\text { Signage, newsletter, driver intervention, } \\
\text { local radio and TV spots }\end{array}$ \\
\hline $\begin{array}{l}\text { Inadequate, homemade ramps at } \\
\text { passenger's home }\end{array}$ & Volunteer groups \\
\hline No ramp available & Volunteer groups \\
\hline $\begin{array}{l}\text { No sidewalk so driver cannot push wheel- } \\
\text { chair from door to vehicle }\end{array}$ & $\begin{array}{l}\text { Help from EMS, operations manager, } \\
\text { transit manager, another driver, or } \\
\text { neighbors }\end{array}$ \\
\hline Limbs obstructing driveway & $\begin{array}{l}\text { Volunteer groups, city, county or state } \\
\text { agencies }\end{array}$ \\
\hline Ruts in driveway & Volunteer groups, family members \\
\hline Fallen trees in driveway & Volunteer groups, family members \\
\hline Driveway too long to drive down & DSS/Agencies \\
\hline Driveway too steep & DSS/Agencies \\
\hline $\begin{array}{l}\text { Hearing -impaired rider will not hear driver } \\
\text { blowing the horn }\end{array}$ & $\begin{array}{l}\text { Rider instructed to watch for the van and } \\
\text { driver goes to the front door or window }\end{array}$ \\
\hline
\end{tabular}


The Department of Social Services and individual agencies can also help to educate parents about the importance of approved safety seats when their children ride in the van and can explain how to obtain these seats free of charge from the local fire department. The fire department currently trains parents in the correct use of the safety seats. The DSS can further decrease rider error by educating riders about the need to cancel pick-ups if their plans change.

The preceding discussion illustrates that the people component of the system can help address many of the errors at this service link. In particular, better education of the riders and agencies in their roles as paratransit customers represents a promising fail-safe approach.

Fail-safe methods that deal with the systems component of service delivery can also be used at this link. For instance, the transit manager regularly addresses the problem of physical barriers to boarding. If low tree branches obstruct access to a rider's driveway, either the transit manager or the operations manager will inspect the problem. Usually, they ask the city utility service to clear away the overhanging tree limbs. In this transit system, volunteers from the local churches and the Senior Center help to fix ruts in riders' driveways or clear fallen trees from driveways. Volunteers also build safe ramps for riders who need but cannot afford them. As mentioned earlier, safe ramps are essential to boarding safety; a driver may refuse to board a rider if the ramp appears unsound. If a rider's yard is inaccessible, the driver can call the local Emergency Medical Service (EMS), the operations manager, or the transit manager for immediate help with the passenger.

Service problems and potential fail-safe solutions for the Transport link are summarized in Table 4. This table reveals that some of the technical mistakes that drivers make, such as following too closely or driving too fast, stem from insufficient time to complete the route safely. Poor planning by the driver can cause this time shortage, but so can schedule creep from no-shows and delays that riders cause during pick-ups. If a driver attempts to compensate for these delays with aggressive driving, accidents can occur. Thus, fail-safe measures that address no-shows and rider-generated delays at earlier service links may help reduce the likelihood of accidents during transport.

Driver training, vehicle inspection, and managerial observation of driver performance also constitute fail-safe methods for the Transport link. Training classes can target various issues, such as driving techniques, dealing with disruptive passengers, first aid/CPR, and drug and alcohol awareness. Reinforcement of material covered in training classes also serves as a fail-safe method. For instance, a sign with 


\section{Table 4. Transport Link: Problem Causes and Fail-Safe Solutions}

\begin{tabular}{|c|c|}
\hline Problem Causes & Fail-Safe Solutions \\
\hline \multirow[t]{4}{*}{ Driving too fast } & $\begin{array}{l}\text { Not allowing appropriate amount of time to } \\
\text { complete the route }\end{array}$ \\
\hline & Poor planning by the driver \\
\hline & $\begin{array}{l}\text { Drivers instructed to drive } 5 \mathrm{mph} \text { below } \\
\text { speed limit on secondary roads }\end{array}$ \\
\hline & $\begin{array}{l}\text { Drivers instructed not to exceed } 60 \mathrm{mph} \text { on } \\
\text { highways and interstates }\end{array}$ \\
\hline Following too closely & $\begin{array}{l}\text { Manager observation of driving habits; } \\
\text { Training }\end{array}$ \\
\hline \multirow[t]{2}{*}{ Erratic driving habits } & Manager observation of driving habits \\
\hline & Manager rates driver's performance \\
\hline Driver inattention & Retraining \\
\hline Poor road conditions & Alternate routing \\
\hline On-board distractions & Passenger conduct rules enforced \\
\hline \multirow[t]{3}{*}{ Driver impairment } & Driver physicals; testing \\
\hline & Driver trained to call for assistance \\
\hline & Drug/alcohol training \\
\hline \multirow[t]{6}{*}{ Equipment malfunction } & Daily inspection preoperation by driver \\
\hline & Daily inspection by driver during operation \\
\hline & 6,000 mile oil change and inspection \\
\hline & Annual vehicle inspection \\
\hline & Spot inspection by managers \\
\hline & Incident report \\
\hline \multirow[t]{2}{*}{ Rude passenger behavior } & Passenger conduct rules enforced \\
\hline & Incident report \\
\hline Passenger is frightened & Driver trained to reassure passenger \\
\hline \multirow[t]{2}{*}{ Wheelchair not properly secured } & $\begin{array}{l}\text { Check for correct fastening at all } 4 \text { points } \\
\text { prior to transport }\end{array}$ \\
\hline & $\begin{array}{l}\text { Check seat belt and shoulder strap prior to } \\
\text { transport }\end{array}$ \\
\hline \multirow[t]{3}{*}{ Passenger illness/accident } & Hazard treatment kits \\
\hline & Incident report \\
\hline & Annual first aid and CPR training \\
\hline
\end{tabular}

a single question about correct safety procedure (e.g. "How should you hold a baby to administer CPR?") can be placed where drivers will see it before they begin their route. The manifest pick-up point is a good location for such "memory ticklers."

The preceding discussion shows that many of the fail-safe methods appropriate to this link involve the people component to a large extent; however, the technology 
component also plays a critical role. Since mechanical failure can cause serious safety problems with the vehicle or lift equipment, preventive maintenance failsafe methods are especially important. For instance, at this system, each van driver must inspect his vehicle prior to beginning his route. Among other things, the driver must measure air pressure in the tires and check the oil level for the engine, the coolant level, the power steering fluid level, and brake fluid level. After completing the inspection, the driver must complete the pretrip inspection form and note any problems with the vehicle. He must then either correct the problem or request another van. Prior to using the replacement van, the driver must conduct an inspection and complete a pretrip form for the new van. If the manager discovers that a driver either overlooked a problem or did not report it on the pretrip form, the manager will do the pretrip inspection with the driver until the manager determines he need no longer do so. The 6,000 mile oil change and inspection for each vehicle also captures how well each driver maintains his or her vehicle.

\section{Testing the Effectiveness of Fail-Safe Methods}

After a manager implements fail-safe methods, he needs to gauge their effectiveness. There is no way for a manager to know if the new methods actually improved service quality unless he selects and monitors performance metrics for those aspects of service he was trying to fail-safe. For instance, at this transit system, the manager created a demand response form to capture data on assigned pick-up times and actual pick-up times for each rider. The data enabled the manager to estimate variances in pick-up times and determine if the system was doing a better job in reducing wait times for passengers. Analysis revealed that a slight variance reduction $(<5 \%)$ occurred after driver training classes placed increased emphasis on meeting pick-up times.

Similarly, the manager collected data on the number of riders that were "no-shows" when the van arrived for pick-ups. This type of data was useful for determining if fail-safe measures helped riders do a better job of being ready for pick-up. Analysis showed that reminder phone calls to elderly riders who were frequent no-shows reduced the no-show rate for this particular group by 50 percent. Analysis also showed that the call-ahead policy to nursing homes whose patients were habitually late resulted in an almost 100 percent improvement in the problem.

Another set of metrics for this system reveals the effectiveness of the fail-safe methods for preventive maintenance. As mentioned earlier, a variety of methods 
such as pretrip inspections, pretrip inspection forms, spot checks by the system manger and the operations manager, the 6,000-mile oil change and inspection, and an annual inspection are used to make preventive maintenance fail-safe. Results reveal that the number of wrecker calls for disabled vans declined by 90 percent. The severity of the problems also declined; before preventive maintenance was made fail-safe, many wrecker calls involved serious mechanical failures like broken axles or brake failures. After fail-safe procedures were initiated, most wrecker calls involved a flat tire or a vehicle stuck on a muddy or flooded road. Other performance metrics confirmed the effectiveness of the fail-safe methods for preventive maintenance: tire wear improved from 18,000 miles before the failsafe program began to 30,000 miles afterward, while brake lining wear increased from 14,000 miles to 40,000 miles.

The manager also used the wrecker calls, tire wear, and brake wear metrics to gauge the effectiveness of the driver training programs. These metrics and tire wear patterns are also used to compare driver performance and identify which drivers exhibit erratic driving techniques.

In addition to collecting operating data to assess service quality, the transit manager gathered information on perceived service quality from customers and analyzed their suggestions and complaints. The manager at this system routinely administered a survey on needs and resources to agencies served by the system. This survey consisted of both scaled questions and open-ended questions. The scaled questions dealt with such issues as overall satisfaction with paratransit service, timely provision of service, dependability of service, professional skills of the drivers, interpersonal skills of the drivers, and courteous and professional treatment by front-office employees. The open-ended questions asked what the system could do to improve service to the agencies and their clients, what agencies considered the major shortfalls in current service, and what gaps existed in transporting clients. Analysis of the comments revealed that not all clients were aware of the range of transit services provided by this system and that some customers simply did not understand how to use the system properly. For instance, one respondent did not realize that transport of patients on oxygen was already available, while others felt that the system was not responsive to the timing of their scheduling requests. The manager decided that "refresher" training sessions for clients at participating agencies would be helpful. At such sessions, the trainer could not only review the procedures for requesting service but also explain why certain rules were in place. 
In addition to explaining how to use paratransit services, the trainer at these sessions could also distribute wallet-sized cards listing the most important rules a rider must follow. Some attendees may benefit from having a handy "reminder card" to help them remember what to do to successfully access services. If the print is easy to read and the color of the cards is bright, riders may be more likely to keep them and refer to them.

\section{Managerial Implications}

The purpose of this study was to illustrate that fail-safe methods constitute a simple, low-tech, low-cost approach to reducing errors that could lead to safety problems in paratransit operations. While a small paratransit system served as the study's research context, the methodology presented in this article is applicable to other transit operations and to nontransit services.

Results from this study showed that at this transit system, fail-safe measures that targeted a specific rider group were far more effective in reducing mistakes than more generic fail-safe methods. For instance, the "call ahead" policy resulted in almost 100 percent improvement on delays caused when nursing home patients were not ready for pick-up. In contrast, an increased emphasis on drivers' attention to pick-up times produced only slight improvement $(<5 \%)$ in pick-up time variances.

This study also reveals that paratransit managers should not rely just on technology solutions to prevent service errors, because safety problems can arise from a variety of interactions within the service system. These interactions may be complex and may involve transit workers, riders, health care providers, vehicles, equipment, software, operating procedures and control systems. Safety problems can also arise from the combined effect of several relatively small mistakes. Technology alone cannot eliminate these mistakes or control all possible interactions in the system. Instead, a comprehensive fail-safe methodology that simultaneously addresses the people, technology and systems components of service delivery at each stage in the service process can help the manager anticipate and prevent mistakes that compromise service safety.

It is important to recognize that paratransit service is a multistage process. Moreover, the individual stages are not independent. Some problems that occur at later stages actually began with mistakes or service errors that originated at earlier stages. For instance, at the paratransit system in this study, late arrivals, missed 
appointments and poor driving techniques-all of which can endanger a dialysis patient-are partly affected by poor rider participation skills. Riders who are not ready at their pick-up times or are frequent no-shows can cause serious delays in the transport of other passengers. Rider/caregiver training-a fail-safe method based on the people component of service delivery-can reduce the likelihood that poor customer participation skills early in the service delivery process will generate service errors in later service stages.

The fail-safe methodology presented in this study represents a process approach for anticipating the complex interactions that produce safety problems. At this paratransit operation, specific fail-safe solutions were devised and continue to be refined. While these fail-safe solutions were based on cause and effect relationships that were observed or anticipated, they did not involve mathematical modeling techniques. Future research is needed to determine if dynamic quantitative modeling techniques could outperform the seasoned, expert manager using system fail-safe methodology. 


\section{References}

Armstrong, P.K. 1995. A model for analyzing quality in the service delivery process. In: The Service Productivity and Quality Challenge, P. Harker (Ed.). Dordrecht, the Netherlands: Kluwer Academic Publishers, 311-342.

Burkhardt, J. 1999. Mobility changes: Their nature, effects and meaning for elders who reduce or cease driving. Transportation Research Record 1671: 11-19.

Burkhardt, J., and McGavock, A. 1999. Tomorrow's older drivers: Who? How many? What impact? Transportation Research Record 1693: 62-70.

Chase, R., and Bowen, D. 1991. Service quality and the service delivery system: A diagnostic framework. In Service Quality: Multidisciplinary and Multinational Perspectives, S. Brown, B. Edvardsson, and B. Gustavsson, Eds. Lexington, MA: Lexington Books.

Chase, R., and Stewart, D. 1994. Make your service failsafe. Sloan Management Review 35 (3): 35-44.

Einstein, N. 2001. Liability flashpoints in paratransit operations. 2001 APTA Bus and Paratransit Conference: 25-35.

Friman, M., Edvardsson, B., and Garling, T. 1998. Perceived service quality attributes in public transport: Inferences from complaints and negative critical incidents. Journal of Public Transportation 2 (1): 67-89.

Hildebrand, E. 2003. Dimensions in elderly travel behavior: A simplified activitybased model using lifestyle clusters. Transportation 30: 285-306.

Perrow, C. 1984. Normal Accidents: Living with High-Risk Technologies. New York: Basic Books.

Prioni, P., and Hensher, D. 2000. Measuring service quality in scheduled bus services. Journal of Public Transportation 3 (2): 51-74.

Rosenbloom, S. 2001. Sustainability and automobility among the elderly: An international assessment. Transportation 28: 375-408.

Souteriou, A.C., and Hadjinicola, G.C. 1999. Resource allocation to improve service quality perceptions in multistage service systems. Production and Operations Management 8 (3): 221-239.

Stewart, D. 2003. Piecing together service quality: A framework for robust service. Production and Operations Management 12 (2): 246-265. 
Sulek, J. 2004. Statistical quality control in services. International Journal of Services Technology and Management 5 (5/6): 522-531.

Sulek, J.M., Marucheck, A, and Lind, M.R. 2005. Measuring performance in multistage service operations: An application of cause selecting control charts. Journal of Operations Management, forthcoming.

Sulek, J., and Lind, M. 2000. A systems model for evaluating transit performance. Journal of Public Transportation 3 (1): 29-48.

\section{About the Authors}

JOANNE M. SULEK (Sulekj@ncat.edu) is a full professor at the School of Business and Economics at North Carolina A\&T State University, where she has been a member of the faculty since 1986. She earned a Ph.D. in Business Administration from the University of North Carolina at Chapel Hill. She has published in numerous journals, including Management Science, Decision Sciences, the Journal of Public Transportation, IEEE Transactions on Engineering Management, and others. Her research interests include service quality, quality control, and forecasting.

MARY R. LIND (Lindm@ncat.edu) is a full professor at North Carolina A\&T State University, where she has been a member of the faculty since 1985 . She earned a Ph.D. in Business Administration from the University of North Carolina at Chapel Hill and has over 20 years of college-level teaching experience and 10 years of industry experience in systems design and development. She has over 20 referred journal publications, which include Management Science, Organization Science, the Journal of Public Transportation, and the Information Systems Journal. She has been a member of the board of directors of the Association of Information Systems and the International Conference on Information Systems. 